\title{
A Concept of Automatic Tuning of Longwall Scraper Conveyor Model
}

\author{
Piotr Przystałka, Andrzej Katunin \\ Silesian University of Technology, \\ Institute of Fundamentals of Machinery Design, \\ 18a Konarskiego Street, 44-100, Gliwice, Poland, \\ Telephone: +48322371069 \\ Email: \{piotr.przystalka, andrzej.katunin\}@ polsl.pl
}

\begin{abstract}
The modeling of machines and their operation modes is a key approach for optimization of their performance as well as for avoiding unwanted operational states which may lead to the occurrence of faults, and finally, to the breakdown. The developed model of a machine should be always parametrized, i.e. the certain number of parameters should be selected in the certain ranges. The most of the parameters can be selected based on engineering documentation and experts' knowledge, however, for some of them this knowledge cannot be directly acquired which leads to the parameter uncertainty. One of the approaches allowing selection of these uncertain parameters is a tuning procedure of a model. The paper deals with a concept of heuristic optimization method for automatic tuning of key parameters of longwall scraper conveyor model. In the first part of the paper, the evolutionary algorithm for tuning this model is proposed. In the case study, the merits and limitations of the evolutionary approach are analysed. The obtained results prove that the proposed approach of tuning of the considered model has high practical potential and it may be applied in real mining conditions.
\end{abstract}

\section{INTRODUCTION}

T HE longwall scraper conveyors are the machines used in the mechanized underground coal mines for transporting a coal. Since these machines usually work in extremely difficult operational conditions it is essential to monitor their performance in order to prevent unwanted operational modes and machinery downtime as well as to implement the knowledge obtained from the monitoring process into the redesigning processes which allows increasing their reliability, effectiveness and safety. However, considering the operational conditions in the underground coal mines as well as difficulties in physical access to sources of various signals and difficulties with their measurement, the monitoring of physical working parameters is often limited to few main quantities, which causes that the measurement data is incomplete, and makes the diagnosis and prognosis of these machines difficult. In order to predict an inappropriate behavior of a conveyor and prevent its unwanted operational modes, it is essential to develop a

The research presented in the paper was financed by the National Centre of Research and Development (Poland) within the framework of the project titled "An integrated shell decision support system for systems of monitoring processes, equipment and hazards" carried out in the path B of Applied Research Programme - grant No. PBS2/B9/20/2013. This publication is financed from the statutory funds of the Faculty of Mechanical Engineering of the Silesian University of Technology in 2016 simulator (or mathematical/numerical model) which allows testing various operational scenarios, including the occurrence of various types of faults.

The model-based approach in diagnostics and condition monitoring of underground mines machinery is widely applicable in numerous industrial solutions. To date, many of such models were developed for scraper and belt conveyors. For the mentioned purposes, Cenacewicz, Przystałka and Katunin [1], [2] developed the models of belt and scraper conveyors for evaluation of their dynamical behavior under certain operational scenarios.

In the most cases, modeling of dynamic behavior of such machinery is difficult, since many operational parameters are not available or even not measurable or impossible to acquire. This leads to the incompleteness and uncertainty of a developed model. Thus, in order to achieve such parameters one can perform simplifications of the model, assume them basing on literature data and experts' knowledge, or use knowledge discovery and optimization techniques. Currently, the most common approach in this task is the manual adjustment of values of behavioural parameters of the model taking into account the data included in technical documentation or in domain literature as well as domain expert's knowledge. Obviously, such an approach is ineffective and leads to the increasing error with an increase of number of uncertain parameters and overall level of model uncertainty. On the other hand, in the recent years, heuristic methods based on the natural phenomena of evolution, such as simulated annealing algorithm, genetic algorithms, differential evolution, harmony or tabu search ideas, swarm-inspired methods, etc. have been developed and applied to model and solve real-life global optimization problems [3]. Furthermore, this kind of optimization algorithms has long been applied for tuning values of unknown parameters of different types of models [4], [5].

The problem of unknown parameter estimation is not enough discussed in many studies related to analytical modeling of mining conveyors, see e.g. [6] and [2]. To the best knowledge of the authors of this paper, this is one of the first attempts on applying a heuristic optimization technique for automatic tuning of parameters of longwall scraper conveyor model. The main goal of this study is the introduction of the new approach based evolutionary tuning of the mathematical 
model of the longwall scraper conveyor. This approach allows for adjusting the values of uncertain parameters of the model, and thus make it fully defined. This, in turn, allows for using this model for modeling of various scenarios of operation as well as for diagnosing the considered machine using the model-based diagnostics approach.

\section{CONCEPT OF THE EVOLUTIONARY ALGORITHM FOR TUNING OF CONVEYOR MODEL}

The mathematical model of the considered scraper conveyor consists of the following submodels: model of a doubled main drive, model of auxiliary drive, model of mine breaker and contactor control, power supply model, model of equations of motion, model of masses, and model of motion resistance. A detailed mathematical and phenomenological description can be found in [2].

The dynamic behavior of the described model strongly depends on values of key parameters corresponding to physical properties of the real conveyor system. The total number of these parameters can be declared as $D$. As it is mentioned above, the most of them can be easily established in the direct way because there is the possibility for gauging and quantifying physical properties of the plant. On the other hand, the rest values declared as $\mathbf{x}=\left[\begin{array}{llll}x_{1} & x_{2} & \ldots & x_{d}\end{array}\right]$ can be indirectly found using signals of process variables which are collected during monitoring of the object and simulation of the model. We assume that the number of observed signals (real and simulated) is equal to $J$, whereas the number of experiments (scenarios) is $I$. Henceforth, real $(r)$ and modeled $(m)$ time series that are needed for tuning purposes may be denoted as

$$
\mathbf{y}_{r}^{i j}=\left[\begin{array}{llll}
y_{r}^{i j}(1) & y_{r}^{i j}(2) & \ldots & y_{r}^{i j}(K)
\end{array}\right]
$$

and

$$
\mathbf{y}_{m}^{i j}(\mathbf{x})=\left[\begin{array}{llll}
y_{m}^{i j}(1, \mathbf{x}) & y_{m}^{i j}(2, \mathbf{x}) \ldots y_{m}^{i j}(K, \mathbf{x})
\end{array}\right]
$$

where $j$ is the $j$-th signal (real or artificial) collected in the $i$-th experiment scenario, $K$ is the number of samples.

The main objective of the tuning procedure is to adjust the values of the parameters $x_{1}, x_{2}, \ldots, x_{d}$ in order to obtain the smallest difference between the response of the system and the response predicted by the proposed model for each scenario. Therefore, the optimization problem can be written as follows:

$$
\begin{array}{ll}
\text { Minimize } & C(\mathbf{x})=f\left[\mathbf{y}_{r}^{i j}, \mathbf{y}_{m}^{i j}(\mathbf{x}), I, J, K\right] \\
\text { subject to } & \Omega(\mathbf{x}),
\end{array}
$$

where $f$ represents a function (with constant arguments $I$, $J, K)$ for comparison of two time series, whilst $\Omega$ denotes boundaries and constraints in the optimization process. The optimal solution $\mathrm{x}^{*}$ is found if the criterion function $C$ has a relative minimum value at $\mathbf{x}=\mathrm{x}^{*}$, that means if

$$
\mathbf{x}^{*}=\underset{\mathbf{x} \in \Omega}{\arg \min } C(\mathbf{x}) .
$$

As to be expected, the criterion function $C$ can be formulated in several ways. In this study, the authors propose two variants of this function. The first one is prepared applying the Minkowski distance of order $p$

$$
C(\mathbf{x}, p)=\sum_{i=1}^{I} \sum_{j=1}^{J} \sqrt[p]{\sum_{k=1}^{K}\left|y_{r}^{i j}(k)-y_{m}^{i j}(k, \mathbf{x})\right|^{p}} .
$$

This measure is a metric in a normed vector space which is considered as a generalization of both the Euclidean distance and the Manhattan distance. The second function is composed of three sub-criteria

$$
C(\mathbf{x}, \mathbf{w})=w_{1} C_{1}(\mathbf{x})+w_{2} C_{2}(\mathbf{x})+w_{3} C_{3}(\mathbf{x}),
$$

where $w_{1}, w_{2}$ and $w_{3}$ are used in order to control the significance of each component. The first criterion function in equation (4) is grounded on the mean absolute percent error and therefore it can be written as

$$
C_{1}(\mathbf{x})=\frac{100}{I J K} \sum_{i=1}^{I} \sum_{j=1}^{J} \sum_{k=1}^{K}\left|\frac{y_{r}^{i j}(k)-y_{m}^{i j}(k, \mathbf{x})}{z^{j}}\right|,
$$

where $z^{j}$ corresponds to the range of the $j$-th sensor.

The second function is declared making use of crosscorrelation as the base of a measure of the total lag $\tau$ between real and simulated signals

$$
C_{2}(\mathbf{x})=\tau=\sum_{i=1}^{I} \sum_{j=1}^{J} \tau^{i j}\left[R_{x y}\left(\mathbf{y}_{r}^{i j}, \mathbf{y}_{m}^{i j}(\mathbf{x})\right)\right] .
$$

The last component is used in order to find the aggregate value of the maximum absolute errors which are present in signals collected under all scenarios

$$
C_{3}(\mathbf{x})=\sum_{i=1}^{I} \sum_{j=1}^{J} \max \left|\frac{\mathbf{y}_{r}^{i j}-\mathbf{y}_{m}^{i j}(\mathbf{x})}{z^{j}}\right| .
$$

The solution of the optimization problem can be found using a limited number of strategies. Derivative-based approaches cannot be employed in this paper, mainly due to the form of the objective function $C$. Moreover, one can easily observe, that the return value of this function depends on the measurement noise in the real-world data as well as the virtual measurements (with simulated disturbances, noise and computing errors as well) obtained during numerical computations. In contrast, pure stochastic optimization methods, for example, Monte Carlo techniques will not be able to find an accurate solution with guaranteeing polynomial-time convergence because of the time of numerical computations of the conveyor model. Therefore, the authors decided to use the evolutionary algorithm which is known as one of the most common heuristic optimization methods. 


\section{CASE STUDY}

\section{A. Description of JOY BLS conveyor and its operating sce-} narios

The developed mathematical model was based on construction and parameters of the scraper conveyor of type $\mathrm{JOY}^{\circledR}$ BLS with the doubled and auxiliary drives. The parametrization of the described simulator was performed based on technical documentation of the modeled conveyor, and data available in the literature [7], [8]. The developed model is characterised by nearly fifty adjustable parameters. The operational parameters were determined theoretically or selected basing on the experts' knowledge.

The simulator of a scraper conveyor provides a possibility of simulation of eight operating scenarios, which represent the characteristic considering the operations performed during work such as idle run-up, idle run-up and run-down, etc. For the performed study four of them were selected due to the significant differences between these scenarios.

One should mention that some of operational parameters cannot be measured and were assumed according to literature data and technical data sheets. Therefore, it is essential to tune up the model in order to simulate its behavior during realization of considered scenarios properly. The five parameters $(d=5)$ that are subject to the tuning process in this study are as follows: the efficiency of the drive system: $x_{1}=\eta$ [-]; the damping factor: $x_{2}=\mu[-]$; the torque losses of flexible and hydrodynamic couplings: $x_{3}=\Delta M_{p}[\mathrm{Nm}]$; the approximation friction coefficient: $x_{4}=a$ [-]; the unitary mass of excavated material: $x_{5}=m_{u}[\mathrm{~kg} / \mathrm{m}]$. These parameters are selected since it is not possible to obtain their values in the direct way.

\section{B. Tuning experiments and results}

The verification tests were carried out with the assumption corresponding to the process variables collected during operational states of the machine. It was decided that only nine process variables $(J=9)$ could be used for tuning: the load of the engines $y_{1}=M_{g n}[\mathrm{Nm}]$; the torque of the engines $y_{2}=M_{n}[\mathrm{Nm}]$; the linear velocity of the chain $y_{3}=v_{n}[\mathrm{~m} / \mathrm{s}]$; the phase currents of the first and second engine $y_{4}=I N Z 1 A, y_{5}=I N Z 1 B, \ldots, y_{9}=I N Z 2 C$ [A] (see [2] for details).

It was also assumed that the sampling rate of the sensors was equal to $500 \mathrm{~Hz}$, whereas the analog-to-digital converter resolution was set to $32 \mathrm{bits}$. The noise powers of selected signals were as follows: $\sigma_{v_{n}}=10 \mathrm{E}-08, \sigma_{M g n}=\sigma_{M p g}=$ $100, \sigma_{I}=10 \mathrm{E}-02$. The reference signals $\mathbf{y}_{r}^{i j}$ were gathered while simulation of the model for selected scenarios ( $I=$ 4 ). The optimal values of parameters were chosen as follows: $x_{1}^{r}=0.957, x_{2}^{r}=0.1, x_{3}^{r}=5, x_{4}^{r}=3$ and $x_{5}^{r}=461.54$. The time of the simulation was set to $40 \mathrm{~s}$. The error measure in the form of

$$
\delta x=\frac{100 \%}{d} \sum_{i=1}^{d} \delta x_{i}=\frac{100 \%}{d} \sum_{i=1}^{d}\left|\frac{x_{i}^{r}-x_{i}^{*}}{x_{i}^{r}}\right|,
$$

was defined in order to evaluate the performance results.

The evolutionary algorithm implemented in Global Optimization Toolbox of Matlab ${ }^{\circledR}$ software was applied in this paper. For each optimization experiment, the boundary values of parameters were chosen taking into account literature data: $0.8 \leq x_{1} \leq 0.99,0 \leq x_{2} \leq 10,2 \leq x_{3} \leq 8,2 \leq x_{4} \leq 4$, $300 \leq x_{5} \leq 570$. In the first step, the performance of the evolutionary algorithm was examined through analysing the influence of the variant of the criterion function $C$ and the values of its parameters. The feasible population method was adapted to create a random well-dispersed initial population satisfying all constraints and bounds. Fitness scaling was done using the rank method, whereas the selection of the parents to the next generation was obtained by means of the stochastic uniform method. The elite count $\delta_{s}=2$ and crossover fraction $p_{c}=0.8$ were chosen. The heuristic crossover function was employed with the user-defined parameter $\lambda_{h}=1.2$. The remaining individuals were mutated with the use of the adaptive feasible method. The population size was equal to 50 , whilst the total number of generations was set to 20 . Nine trials were performed in this part of the study: trials from 1 to 5 - fitness function was declared using Eq. (3) for $p=\{1,2, \ldots, 5\}$; trials from 6 to 9 - fitness function was declared using Eq. (4) for $\mathbf{w}=\left[\begin{array}{lll}1 & 0 & 0\end{array}\right], \mathbf{w}=\left[\begin{array}{lll}0 & 1 & 0\end{array}\right]$, $\mathbf{w}=\left[\begin{array}{lll}0 & 0 & 1\end{array}\right], \mathbf{w}=\left[\begin{array}{lll}0.9 & 0.01 & 0.09\end{array}\right]$.

The results of experiments from this stage of the study are included in the first part of Table I. It can be stated that in the average sense, the minor errors can be achieved using the criterion function $C$ in the form of Eq. 3. For this function, in each case beyond the 5 th trial the mean error $\delta x$ was close to $10 \%$. Nevertheless, the smallest error was reached for the second criterion function that has been declared using Eq. 4 with $\mathbf{w}=\left[\begin{array}{lll}0.9 & 0.01 & 0.09\end{array}\right]$. Hence, this variant of the fitness function was used in the next two steps.

In the second step, the authors analysed the influence of the population size and the crossover probability on the performance of the evolutionary algorithm. In order to examine this issue six experiments were conducted: trials 10 and 11 - fitness function was declared using Eq. (4) for $\mathbf{w}=\left[\begin{array}{lll}0.9 & 0.01 & 0.09\end{array}\right]$ and the population size was equal to $\{30,40\}$, the rest properties were the same as in the first step; trials from 12 to 14 - fitness function was declared using Eq. (4) for $\mathbf{w}=\left[\begin{array}{lll}0.9 & 0.01 & 0.09\end{array}\right]$ and the crossover fraction was equal to $\{0.6,0.7,0.9\}$, the rest properties were the same as in the first step; trial 15 - fitness function was declared using Eq. (4) for $\mathbf{w}=\left[\begin{array}{lll}0.9 & 0.01 & 0.09\end{array}\right]$, the population size was equal to 50 and the crossover fraction was equal to 0.7 , the rest properties were the same as in the first step. This part of the research led us to state that, the smallest error could be achieved with the use of 20 individuals in the population, whereas the crossover fraction should be set to 0.7 . It is easy to observe that, these settings can provide the mean error result smaller than $5 \%$.

In the last part of the study, the analysis of the accuracy of the evolutionary optimization was carried out in the context of the sampling rate and resolution as well as the number 
TABLE I: The errors and final values of parameters determined by the evolutionary optimization algorithm

\begin{tabular}{|c|c|c|c|c|c|c|}
\hline $\begin{array}{l}\text { Trial } \\
\text { No. }\end{array}$ & $\begin{array}{c}x_{1}^{*}[-] \\
\delta x_{1}[\%]\end{array}$ & $\begin{array}{c}x_{2}^{*}[-] \\
\delta x_{2}[\%]\end{array}$ & $\begin{array}{l}x_{3}^{*}[\mathrm{Nm}] \\
\delta x_{3}[\%]\end{array}$ & $\begin{array}{c}x_{4}^{*}[-] \\
\delta x_{4}[\%]\end{array}$ & $\begin{array}{c}x_{5}^{*}[\mathrm{~kg}] \\
\delta x_{5}[\%]\end{array}$ & $\delta x[\%]$ \\
\hline \multicolumn{7}{|c|}{ 1st step } \\
\hline 1 & $\begin{array}{c}0.949 \\
0.75\end{array}$ & $\begin{array}{c}0.13 \\
30.64\end{array}$ & $\begin{array}{c}6.33 \\
26.76\end{array}$ & $\begin{array}{l}3.01 \\
0.46\end{array}$ & $\begin{array}{c}457.95 \\
0.78\end{array}$ & 11.88 \\
\hline 2 & $\begin{array}{c}0.950 \\
0.72\end{array}$ & $\begin{array}{l}0.09 \\
1.76\end{array}$ & $\begin{array}{c}2.91 \\
41.79\end{array}$ & $\begin{array}{l}3.02 \\
0.76\end{array}$ & $\begin{array}{c}455.64 \\
1.28\end{array}$ & 9.26 \\
\hline 3 & $\begin{array}{c}0.958 \\
0.14\end{array}$ & $\begin{array}{c}0.11 \\
13.97\end{array}$ & $\begin{array}{c}7.00 \\
40.09\end{array}$ & $\begin{array}{l}3.00 \\
0.08\end{array}$ & $\begin{array}{c}462.21 \\
0.15\end{array}$ & 10.89 \\
\hline 4 & $\begin{array}{c}0.956 \\
0.09\end{array}$ & $\begin{array}{c}0.08 \\
12.26\end{array}$ & $\begin{array}{c}3.37 \\
32.49\end{array}$ & $\begin{array}{l}3.00 \\
0.02\end{array}$ & $\begin{array}{c}461.23 \\
0.07\end{array}$ & 8.98 \\
\hline 5 & $\begin{array}{c}0.941 \\
1.60\end{array}$ & $\begin{array}{c}0.20 \\
102.19\end{array}$ & $\begin{array}{l}4.59 \\
8.08\end{array}$ & $\begin{array}{l}2.93 \\
2.26\end{array}$ & $\begin{array}{c}471.84 \\
2.23\end{array}$ & 23.27 \\
\hline 6 & $\begin{array}{c}0.919 \\
3.96\end{array}$ & $\begin{array}{c}0.27 \\
170.47\end{array}$ & $\begin{array}{c}2.25 \\
54.87\end{array}$ & $\begin{array}{c}2.67 \\
10.79\end{array}$ & $\begin{array}{c}507.01 \\
9.85\end{array}$ & 49.99 \\
\hline 7 & $\begin{array}{c}0.873 \\
8.76\end{array}$ & $\begin{array}{c}0.29 \\
192.92\end{array}$ & $\begin{array}{l}5.32 \\
6.48\end{array}$ & $\begin{array}{c}2.33 \\
22.02\end{array}$ & $\begin{array}{c}405.70 \\
12.10\end{array}$ & 48.46 \\
\hline 8 & $\begin{array}{c}0.899 \\
6.03\end{array}$ & $\begin{array}{l}0.061 \\
38.74\end{array}$ & $\begin{array}{c}2.01 \\
59.62\end{array}$ & $\begin{array}{l}3.06 \\
2.08\end{array}$ & $\begin{array}{c}409.92 \\
11.18\end{array}$ & 23.53 \\
\hline 9 & $\begin{array}{c}0.955 \\
0.21\end{array}$ & $\begin{array}{l}0.10 \\
4.78\end{array}$ & $\begin{array}{c}6.18 \\
23.72\end{array}$ & $\begin{array}{l}2.87 \\
4.13\end{array}$ & $\begin{array}{c}486.54 \\
5.42\end{array}$ & 7.65 \\
\hline \multicolumn{7}{|c|}{ 2nd step } \\
\hline 10 & $\begin{array}{c}0.958 \\
0.18\end{array}$ & $\begin{array}{l}0.09 \\
3.27\end{array}$ & $\begin{array}{c}7.88 \\
57.67\end{array}$ & $\begin{array}{l}2.99 \\
0.19\end{array}$ & $\begin{array}{c}463.24 \\
0.37\end{array}$ & 12.33 \\
\hline 11 & $\begin{array}{c}0.934 \\
2.36\end{array}$ & $\begin{array}{c}0.06 \\
32.17\end{array}$ & $\begin{array}{c}2.84 \\
43.11\end{array}$ & $\begin{array}{l}2.98 \\
0.66\end{array}$ & $\begin{array}{c}450.75 \\
2.34\end{array}$ & 16.13 \\
\hline 12 & $\begin{array}{c}0.959 \\
0.23\end{array}$ & $\begin{array}{c}0.26 \\
165.68\end{array}$ & $\begin{array}{c}3.90 \\
21.93\end{array}$ & $\begin{array}{l}2.86 \\
4.53\end{array}$ & $\begin{array}{c}492.54 \\
6.72\end{array}$ & 39.82 \\
\hline 13 & $\begin{array}{c}0.957 \\
0.06\end{array}$ & $\begin{array}{l}0.10 \\
6.74\end{array}$ & $\begin{array}{c}5.66 \\
13.34\end{array}$ & $\begin{array}{l}2.99 \\
0.19\end{array}$ & $\begin{array}{c}463.24 \\
0.37\end{array}$ & 4.14 \\
\hline 14 & $\begin{array}{c}0.941 \\
1.64\end{array}$ & $\begin{array}{c}0.14 \\
46.92\end{array}$ & $\begin{array}{c}6.34 \\
26.90\end{array}$ & $\begin{array}{l}3.04 \\
1.65\end{array}$ & $\begin{array}{c}440.88 \\
4.48\end{array}$ & 16.32 \\
\hline 15 & $\begin{array}{c}0.958 \\
0.19\end{array}$ & $\begin{array}{l}0.10 \\
4.83\end{array}$ & $\begin{array}{c}6.92 \\
38.49\end{array}$ & $\begin{array}{l}3.00 \\
0.10\end{array}$ & $\begin{array}{c}461.55 \\
0.00\end{array}$ & 8.72 \\
\hline \multicolumn{7}{|c|}{ 3rd step } \\
\hline 16 & $\begin{array}{c}0.965 \\
0.92\end{array}$ & $\begin{array}{c}0.18 \\
80.97\end{array}$ & $\begin{array}{c}7.86 \\
57.29\end{array}$ & $\begin{array}{l}2.96 \\
1.22\end{array}$ & $\begin{array}{c}474.40 \\
2.79\end{array}$ & 28.64 \\
\hline 17 & $\begin{array}{c}0.954 \\
0.22\end{array}$ & $\begin{array}{l}0.09 \\
1.63\end{array}$ & $\begin{array}{c}3.52 \\
29.60\end{array}$ & $\begin{array}{l}3.00 \\
0.09\end{array}$ & $\begin{array}{c}459.83 \\
0.37\end{array}$ & 6.38 \\
\hline 18 & $\begin{array}{c}0.943 \\
1.38\end{array}$ & $\begin{array}{c}0.08 \\
13.24\end{array}$ & $\begin{array}{c}2.53 \\
49.31\end{array}$ & $\begin{array}{l}2.97 \\
0.69\end{array}$ & $\begin{array}{c}456.95 \\
0.99\end{array}$ & 13.12 \\
\hline
\end{tabular}

of the available sensors. The last three trials were done as follows: trial 16 - fitness function was declared using Eq. (4) for $\mathbf{w}=\left[\begin{array}{lll}0.9 & 0.01 & 0.09\end{array}\right]$, only three sensors were used $v_{n}$, $I N Z 1 A$ and $I N Z 2 A$, the rest properties were the same as in the second step; trial 17 - fitness function declared using Eq. (4) for $\mathbf{w}=\left[\begin{array}{lll}0.9 & 0.01 & 0.09\end{array}\right]$, all sensors were used, the sampling rate was equal to $1 \mathrm{~Hz}$, the resolution was set to 16bits, the rest properties were the same as in the second step; trial 18 - fitness function declared using Eq. (4) for $\mathrm{w}=$ $\left[\begin{array}{lll}0.9 & 0.01 & 0.09\end{array}\right]$, only three sensors were used $v_{n}, I N Z 1 A$ and $I N Z 2 \mathrm{~A}$, the sampling rate was equal to $1 \mathrm{~Hz}$, the resolution was set to 16bits, the rest properties were the same as in the second step.

The last analysis is very important from a technical point of view. It can be pointed out, that in mining engineering practice it is possible to use measuring devices with lower sampling rate and resolution for accurate tuning of a longwall scraper conveyor model. The sampling rate equals to $1 \mathrm{~Hz}$ with the resolution equals to 16bits can be enough for this kind of problems to have the mean error significantly less than $10 \%$ provided that it involves the required number of measuring sensors.

Taking into account overall results of the study presented in Table I it can be concluded that the most important parameter is the damping factor. Even a small change in the value of this parameter can have a strong influence on the results of the simulation. On the other hand, the value of the loss of the torques of flexible and hydrodynamic couplings has almost no effect on the simulation.

\section{Conclusions}

In this paper, the authors proposed and verified a concept of the heuristic optimization method for tuning values of parameters of longwall scraper conveyor model. In the considered model five of parameters were defined as uncertain, and the tuning problem was defined over these parameters. In turn, nine output parameters of the longwall scraper conveyor model were selected for tuning procedures. The tuning procedure was performed using four selected operational scenarios which were the most representative for the performed task.

The authors have formulated the optimization problem and applied the evolutionary computation in order to find the final solution. Two kinds of the criterion function was proposed. The first one was based on Minkowski's distance, whilst the second was prepared by means of weighted sub-criteria such as the mean absolute percent error, the cross-correlation function and the aggregate value of the maximum absolute errors. It was shown that the second type of the criterion function should be used in order to obtain the smallest mean errors during searching optimal values of parameters. The validation tasks confirm that the proposed tuning method is characterized by the high precision of tuning of uncertain parameters of the model, and may be successfully applied in real mining conditions.

\section{REFERENCES}

[1] K. Cenacewicz and P. Przystałka, "Conveyor belt simulator with fault models," Modelling in Engineering, vol. 24, no. 55, pp. 13-20, 2015, [in Polish].

[2] K. Cenacewicz and A. Katunin, "Modeling and simulation of longwall scraper conveyor considering operational faults," Studia Geotechnica et Mechanica, vol. 38, no. 2, pp. 15-27, 2016. [Online]. Available: http://dx.doi.org/10.1515/sgem-2016-0015

[3] A. Mucherino and O. Seref, Advances in Modeling Agricultural Systems. Boston, MA: Springer US, 2009, ch. Modeling and Solving Real-Life Global Optimization Problems with Meta-heuristic Methods, pp. 403419. [Online]. Available: http://dx.doi.org/10.1007/978-0-387-75181-8_ 19

[4] P. M. Vasant and P. M. Vasant, Handbook of Research on Novel Soft Computing Intelligent Algorithms: Theory and Practical Applications, 1st ed. Hershey, PA, USA: IGI Global, 2013.

[5] J. Valadi and P. Siarry, Applications of Metaheuristics in Process Engineering. Springer Publishing Company, Incorporated, 2014.

[6] M. Dolipski, E. Remiorz, and P. Sobota, "Determination of dynamic loads of sprocket drum teeth and seats by means of a mathematical model of the longwall conveyor," Archives of Mining Sciences, vol. 57, no. 4, pp. 1101-1119, 2012. [Online]. Available: http: //dx.doi.org/10.2478/v10267-012-0073-7

[7] M. Dolipski, Dynamics of chain conveyors. Gliwice: The Silesian University of Technology Press, 1997, [in Polish].

[8] A. M. Plamitzer, Electrical machines, 4th ed. Warsaw: WNT, 1976, [in Polish]. 